\title{
Treatment of Brackish Water RO Brine via Bipolar Membrane Electrodialysis
}

Chunliang Du ${ }^{1}$, Jennifer Runhong $\mathrm{Du}^{1, *}$, Xiangshan Zhao ${ }^{1}$, Fang Cheng ${ }^{2}$, Mohamed E.A.

$$
\mathrm{Ali}^{3}, \text { Xianshe Feng }{ }^{4}
$$

${ }^{1}$ State Key Laboratory of Separation Membranes and Membrane Processes, School of Material Science and Engineering, Tiangong University, Tianjin, China

${ }^{2}$ School of Environmental and Municipal Engineering, Tianjin Chengjian University, Tianjin, China

${ }^{3}$ Egyptian Desalination Research Center of Excellence \& Hydrogeochemistry Dept., Desert Research Center, Cairo, Egypt

${ }^{4}$ Department of Chemical Engineering, University of Waterloo, Ontario, Canada

* Corresponding author: Jennifer Runhong Du.

E-mail: durunhong@tiangong.edu.cn 


\subsubsection{Current density}
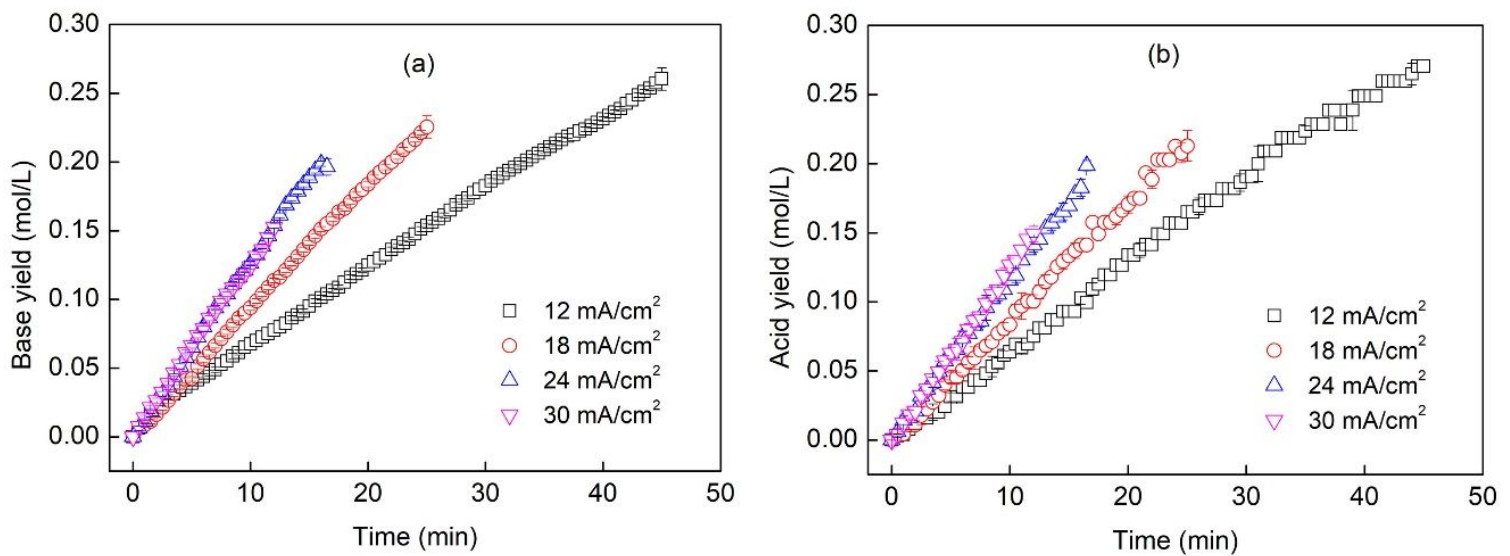

Figure. 1S. Concentration of the produced (a) base and (b) acid vs. time curve at different current densities (Initial $\mathrm{NaCl}$ content: $25 \mathrm{~g} / \mathrm{L} ; \mathrm{Na}_{2} \mathrm{SO}_{4}$ content: $0.5 \mathrm{~mol} / \mathrm{L}$; initial $\mathrm{HCl}$ and $\mathrm{NaOH}$ contents: $0.2 \mathrm{~mol} / \mathrm{L}$ ).

\subsection{Estimates of process costs}

1. Calculation of $\mathrm{NaOH}$ annual production capacity:

(1) BMED can produce $4 \mathrm{~L} \mathrm{NaOH}$ with a concentration of $0.6 \mathrm{~mol} / \mathrm{L}$ within $1.5 \mathrm{~h}$.

(2) Batches operated per year $=$ Working time $(\mathrm{h} /$ year $) \div 1.5 \mathrm{~h}=6000(\mathrm{~h} /$ year $) \div 1.5 \mathrm{~h}=4000$.

(3) The volume of $\mathrm{NaOH}$ solution produced per year $=4000 * 4 \mathrm{~L}=16000 \mathrm{~L} /$ year.

(4) Weight of $\mathrm{NaOH}$ produced per year $=0.6 \mathrm{~mol} / \mathrm{L} * 16000 \mathrm{~L} * 40 \mathrm{~g} / \mathrm{L}=384 \mathrm{~kg} /$ year. 